\title{
A PEDAGOGIA HISTÓRICO-CRÍTICA EM DEFESA DE UMA EDUCAÇÃO REVOLUCIONÁRIA
}

\author{
PEDAGOGÍA HISTÓRICO-CRÍTICA EN DEFENSA DE LA EDUCACIÓN \\ REVOLUCIONARIA
}

\section{HISTORICAL-CRITICAL PEDAGOGY IN DEFENSE OF REVOLUTIONARY EDUCATION}

\author{
Hellen Jaqueline MARQUES ${ }^{1}$ \\ Newton DUARTE ${ }^{2}$
}

RESUMO: A importância da educação está na sua relação com as necessidades humanas e os direitos sociais. Sendo assim, emergem há décadas propostas educativas com diferentes perspectivas de intervenção que buscam atender objetivos e concepções de mundo igualmente distintas. Diante deste cenário, fundamentados no materialismo histórico dialético, apresentaremos uma análise da contribuição da educação escolar para a formação da consciência de classe e emancipação humana. Neste sentido, temos como objetivos debater a especificidade da educação escolar e suas relações com a luta política na sociedade capitalista e apresentar a pedagogia histórico-crítica como alternativa revolucionária. Para além de compreendermos as contribuições dos múltiplos espaços onde ocorrem o ensino e a aprendizagem, elencamos a educação escolar como lócus privilegiado para o acesso e apropriação de conteúdos essenciais e inerentes aos direitos humanos. A pesquisa está pautada na possibilidade de uma educação contra-hegemônica que contribua para a superação das relações sociais de dominação.

PALAVRAS-CHAVE: Educação escolar. Pedagogia histórico-crítica. Conteúdos escolares. Consciência de classe.

RESUMEN: La importancia de la educación está relacionada con las necesidades humanas y los derechos sociales. Así, desde hace décadas han surgido propuestas educativas con diferentes perspectivas de intervención que buscan cumplir con objetivos y visiones del mundo igualmente diferentes. Ante este escenario, a partir del materialismo dialéctico histórico, presentaremos un análisis de la contribución de la educación escolar a la formación de la conciencia de clase y la emancipación humana. En este sentido, buscamos debatir la especificidad de la educación escolar y sus relaciones con la lucha politica en la sociedad capitalista y presentar la pedagogía histórico-crítica como alternativa revolucionaria. Además de comprender los aportes de los múltiples espacios donde se desarrolla la enseñanza y el aprendizaje, enlistamos la educación escolar como un lugar privilegiado de acceso y

\footnotetext{
${ }^{1}$ Universidade Federal de Mato Grosso do Sul (UFMS), Corumbá - MS - Brasil. Docente do Curso de Pedagogia. Doutorado em Educação Escolar (UNESP). ORCID: https://orcid.org/0000-0003-1146-2801. E-mail: hellenjm@gmail.com

${ }^{2}$ Universidade Estadual Paulista Júlio de Mesquita Filho (UNESP), Araraquara - SP - Brasil. Docente do Programa de Pós-Graduação em Educação Escolar. Doutorado em Educação (UNICAMP). ORCID: http://orcid.org/0000-0003-1837-8004. E-mail: newton.duarte@uol.com.br
}

RIAEE - Revista Ibero-Americana de Estudos em Educação, Araraquara, v. 15, n. esp. 3, p. 2204-2222, nov. 2020. e-ISSN: 1982-5587 
apropiación de contenidos esenciales e inherentes a los derechos humanos. La investigación se basa en la posibilidad de una educación antihegemónica que contribuya a superar las relaciones sociales de dominación.

PALABRAS CLAVE: Enseñanza. Pedagogía histórico-crítica. Contenidos escolares. Conciencia de clase.

ABSTRACT: The importance of education is related to human needs and social rights. Thus, educational proposals have emerged for decades with different intervention perspectives that seek to meet equally different goals and worldviews. Given this scenario, based on historical dialectical materialism, we will present an analysis of the contribution of school education to the formation of class consciousness and human emancipation. In this sense, we aim to debate the specificity of school education and its relations with the political struggle in capitalist society and present historical-critical pedagogy as a revolutionary alternative. In addition to understanding the contributions of the multiple spaces where teaching and learning take place, we list school education as a privileged locus for access and appropriation of essential content and inherent to human rights. The research is based on the possibility of a counter-hegemonic education that contributes to overcoming the social relations of domination.

KEYWORDS: School education. Historical-critical pedagogy. School contents. Class consciousness.

\section{Introdução}

A pedagogia histórico-crítica é uma perspectiva pedagógica delineada pelo Professor Dermeval Saviani e debatida por diversos pesquisadores brasileiros ao longo dos últimos anos. Um dos elementos primordiais do debate em torno das contribuições da pedagogia históricocrítica para a formação humana é o seu compromisso político-social com a compreensão da realidade e o potencial transformador da ação humana sobre a mesma. Para tanto, é mister a defesa do papel fundamental que a escola exerce para transmissão e aprendizagem das objetivações humanas mais desenvolvidas. Isso não quer dizer que outras teorias e perspectivas educacionais não possuem aspectos políticos e sociais que determinam e orientam rumos para a educação dos indivíduos.

O papel político desempenhado pelas teorias educacionais é analisado por Saviani (1982) na perspectiva histórica, materialista e dialética, o que o leva, por exemplo, a argumentar que a pedagogia tradicional, em que pese seu caráter de teoria não crítica da educação, desempenhou um papel revolucionário no momento histórico em que a burguesia era classe revolucionária. A questão que se põe é, portanto, a de uma pedagogia que articule de forma crítica e historicizadora a atividade educacional com a construção de uma prática social 
revolucionária, ou seja, uma prática social que se posicione na perspectiva de superação da sociedade burguesa.

Acreditamos assim, que a escola, dialeticamente inserida na sociedade capitalista, pode contribuir para sua superação, pois, das relações que se constroem no interior da escola, também emanam as contradições presentes no processo de formação do ser humano. Para avançar além da adaptação ao status quo, é preciso que os indivíduos suplantem a superficialidade da realidade. É necessária a compreensão da essência do real, reconhecer os nexos que sustentam o modo de organização da sociedade (BATISTA; LIMA, 2012).

Para que o pensamento possa apropriar-se criticamente da realidade objetiva em suas múltiplas determinações e seus movimentos de evolução e involução, revolução e contrarrevolução, é necessário ir além do pensamento empírico e da ação puramente pragmática. Há que se desenvolver o pensamento teórico, capaz de trabalhar com a dialética entre os eventos aparentes e os processos essenciais, o que requer, na escola, a atuação deliberada do professor no sentido da produção do pensamento teórico nos alunos.

Tais reflexões nos levam a destacar o ensino como meio para que as mais ricas objetivações humanas sejam devidamente apropriadas, elevando o grau de desenvolvimento do pensamento e, mais amplamente, do psiquismo em sua integridade. Considerando que, "apenas por sua mediação a realidade será captada em sua gênese em seu desenvolvimento, ou seja, como sintese de múltiplas determinações" (MARTINS, 2011, p. 53).

Destarte, cabe à educação escolar garantir as condições, naquilo que the compete, para o desenvolvimento da consciência transformadora nos indivíduos, "ferramenta" indispensável para que não existam sob imediata ação do meio, mas como sujeitos da história. Esse objetivo não é alcançado nos limites de saberes reiterativos da cotidianidade em detrimento dos conhecimentos clássicos (MARTINS, 2011, p. 55).

Todavia, para que o professor consiga, conscientemente, desencadear este processo, de modo a contribuir efetivamente para essa formação, é preciso que haja a compreensão dos fatores que irão constituir e construir essa necessidade. Nas palavras de Saviani (2008, p. 64),

[...] tal contribuição será tanto mais eficaz quanto mais o professor for capaz de compreender os vínculos da sua prática com a prática social global. [...]. Insisto neste ponto porque, em geral, há a tendência a desvincular os conteúdos específicos de cada disciplina das finalidades sociais mais amplas. Então, ou se pensa que os conteúdos valem por si mesmos sem necessidade de referi-los à prática social em que se inserem, ou se acredita que os conteúdos específicos não têm importância colocando-se todo o peso na luta política mais ampla. Com isso dissolve-se a especificidade da contribuição pedagógica, anulando-se, em consequência, a sua importância política.

RIAEE - Revista Ibero-Americana de Estudos em Educação, Araraquara, v. 15, n. esp. 3, p. 2204-2222, nov. 2020. e-ISSN: 1982-5587 
Contudo, há que se destacar que, segundo Saviani (2008), existe uma diferença entre a educação e a política. São práticas distintas com suas especificidades, e não é sua intenção diluílas, diminuindo seu potencial. Ainda que sejam práticas interdependentes e inseparáveis quando falamos de ação educativa, pois apresentam uma relação interna e outra externa a elas mesmas.

\section{A especificidade da educação e a luta política}

$\mathrm{Na}$ perspectiva dialética, materialista e histórica adotada pela pedagogia históricocrítica, o trabalho intencional e sistemático de ensino realizado pelo professor não se opõe ao caráter ativo da aprendizagem realizada pelo aluno. Ainda que ambos, professor e aluno, possuam graus distintos de consciência da relação pedagógica, a natureza dessa relação não é a de um choque entre forças antagônicas, mas de um movimento de desenvolvimento humano produzido pela ação recíproca de polos opostos. Na política os opostos são antagônicos, o que reflete a necessidade de luta. Assim, precisamos considerar o movimento dialético na relação entre política e educação, pois, há em cada uma, a dimensão da outra.

O desenvolvimento da ação educativa depende da prática política, no sentido de que esta última pode possibilitar as condições para a efetivação da primeira. A questão do financiamento público da educação é alvo de intensa luta, como se observou na recente questão sobre a Proposta de Emenda à Constituição (PEC) do Fundo de Manutenção e Desenvolvimento da Educação Básica e de Valorização dos Profissionais da Educação (FUNDEB), em que o governo de Jair Bolsonaro, por meio do ministro da Economia Paulo Guedes, fez o que pode para tentar impedir sua aprovação ${ }^{3}$. Além dos embates sobre o financiamento da educação, que envolvem também as disputas referentes aos salários dos professores, aos usos das verbas destinadas à educação, etc., existem outras lutas no campo da política educacional, que é o caso, por exemplo, da regulamentação dos currículos escolares, que se tornou, já há algum tempo, terreno de intensa luta ideológica movida pelas forças obscurantistas.

A política está atrelada à educação, na medida em que esta também oferece subsídios para o desenvolvimento das "condições subjetivas" dos sujeitos para sua participação política, como o acesso ao conhecimento (SAVIANI, 2008). Em relação especificamente a essa questão, vale salientar que a criação de barreiras para o acesso ao conhecimento é, na atualidade, uma

${ }^{3}$ As notícias do período ressaltaram a postura do governo diante da PEC. Como exemplo, ver Vargas e Weterman (2020), sobre a tentativa do governo em adiar o processo de votação. Disponível em: https://noticias.uol.com.br/ultimas-noticias/agencia-estado/2020/07/20/governo-tenta-adiar-votacao-do-fundebem-uma-semana.htm. Acesso em: 18 ago. 2020.

RIAEE - Revista Ibero-Americana de Estudos em Educação, Araraquara, v. 15, n. esp. 3, p. 2204-2222, nov. 2020. e-ISSN: 1982-5587 
forte estratégia política, como se verifica no fenômeno das chamadas "fake news" e na guerra ideológica contra a escola e os professores movida pela extrema direita.

Sendo assim, educação e política integram a totalidade da prática social. Todavia, diante da realidade que vivemos, a política é supervalorizada em relação à educação, que está, por sua vez, subordinada (real e relativamente) à política (SAVIANI, 2008). Esta subordinação, de acordo com Saviani (2008), é histórica e não só precisa como deve ser superada.

Isto porque, se as condições de exercício da prática política estão inscritas na essência da sociedade capitalista, as condições de exercício da prática educativa estão inscritas na essência da realidade humana, mas são negadas pela sociedade capitalista não podendo se realizar aí senão de forma subordinada, secundária (SAVIANI, 2008, p. 69).

Neste ponto, é importante pensarmos a formação humana no seio das contradições que permeiam as relações sociais. O que se destacam no movimento dinâmico da educação são pontos de avanços no processo de superação e conscientização tão caro à transformação social e, com isto, a identificação de novas necessidades para o enfrentamento.

Esta compreensão também é resultado da dialética entre a sociedade capitalista, as condições atuais de existência e a plenitude humana, ou a plena realização da prática educativa. Isto é, só podemos vislumbrar a plenitude humana na realidade atual porque ela nos apresenta essa possibilidade. Neste sentido, Saviani (2008, p. 70) afirma que "ser idealista em educação significa justamente agir como se esse tipo de sociedade já fosse realidade. Ser realista inversamente, significa reconhecê-la como um ideal que buscamos atingir". Cabe aqui uma observação sobre o significado com que Saviani (2008) emprega, nesse contexto, o adjetivo "idealista", que não se trata, portanto, de uma pessoa que age movida por um ideal, mas sim como uma atitude de desconsideração das reais condições objetivas nas quais ocorrem as ações.

Para isso é preciso reconhecer o poder que a verdade tem e o potencial que a classe trabalhadora poderá exercer ao se apropriar da verdade. Visto que ela traz consigo a possibilidade de compreensão das relações de dominação e do caminho da universalidade ao invés da alienação. Eis o poder revolucionário daqueles que exercem a função educativa, pois, ao socializarmos o conhecimento, estamos política e pedagogicamente contribuindo para a constituição da humanidade em cada indivíduo, dando-lhe a possibilidade de agir, transformar ou reproduzir, conscientemente (SAVIANI, 2008).

Ademais, por mais que a educação, na sociedade capitalista, esteja (em certo grau) subordinada à política, ela não perde completamente sua autonomia. Não obstante, na ocasião de superação da sociedade dividida em classes, finda-se o "primado da política" e a 
subordinação da educação (SAVIANI, 2008). Para tanto, há que se pensar nas relações entre política e educação na direção de uma visão de mundo revolucionária, do ponto de vista da classe trabalhadora. Isto é, superando a visão de mundo pautada na cotidianidade alienada.

Sendo assim, como afirma Martins (2011), não podemos nos furtar de ações e proposições ativas e transformadoras que superem a mera contemplação e adaptação à realidade criada pelos próprios seres humanos. Ações que necessariamente devem emergir da compreensão do que é a realidade, o mundo no qual o ser humano vive e por meio do qual se realiza. No entanto,

Tais ações exigem, necessariamente, um tipo de pensamento que promova a superação da empiria fetichizada, das aparências - sejam elas falsas ou verdadeiras -, instrumentalizando os indivíduos para a atividade consciente, para a transformação das circunstâncias e de si mesmos. É com essa tarefa que entendemos a educação escolar verdadeiramente emancipadora (MARTINS, 2011, p. 56-57).

Este tipo de educação nos impele a defender e clamar por uma pedagogia que atenda os interesses da classe dominada, que prepare os indivíduos para o enfrentamento em busca da superação das classes sociais, ou seja, uma pedagogia que seja em sua essência revolucionária do ponto de vista do trabalhador, da humanização das relações sociais.

A pergunta que temos que responder, tendo em vista uma pedagogia revolucionária é:

Pretende-se que sempre existam governados e governantes ou pretende-se criar as condições nas quais a necessidade dessa divisão desapareça? Isto é, parte-se da premissa da divisão perpétua do gênero humano ou crê-se que ela é apenas um fato histórico, correspondente a certas condições? (GRAMSCI, 2011, p. 325).

Ao que Saviani aponta:

[...] a pedagogia proposta, uma vez que se pretende a serviço dos interesses populares, terá contra si os interesses até agora dominantes. Trata-se, portanto, de lutar também no campo pedagógico para fazer prevalecer os interesses até agora não dominantes. E esta luta não parte do consenso, mas do dissenso. $\mathrm{O}$ consenso é vislumbrado no ponto de chegada. Para se chegar lá, porém, é necessário, pela prática social, transformar as relações de produção que impedem a construção de uma sociedade igualitária (SAVIANI, 2008, p. 60).

Uma pedagogia que se pretenda revolucionária deve, portanto, partir da própria história e das produções do ser humano no campo educacional. O que nos remete à necessidade de análise e compreensão das teorias pedagógicas e o papel que assumiram ao longo do desenvolvimento da sociedade. Essa atitude apoia-se nos fundamentos do marxismo, posto que 
compreende que não se revoluciona a sociedade a não ser a partir da transformação das condições existentes, empregando-se os meios existentes, reconhecendo-se as possibilidades reais de criação de uma sociedade ainda não existente, mas contida em potência nas forças sociais colocadas em movimento pelos próprios seres humanos.

Quando ouvimos com frequência, tanto a alguns representantes da juventude, como a certos defensores dos novos métodos de ensino, atacar a velha escola, alegando que se limitava a fazer decorar os textos, respondemos que, apesar disso, se deve aproveitar dela tudo o que tinha de bom. [...] Não queremos um ensino mecânico, mas necessitamos de desenvolver e aperfeiçoar a memória de cada estudante, proporcionando-lhe fatos essenciais, porque o comunismo seria um vácuo, ficaria reduzido a uma fachada incaracterística, o comunista não passaria de um fanfarrão, se não compreendesse e assimilasse todos os conhecimentos adquiridos (LENINE, 1977, p. 126).

Por isso, o debate contemporâneo sobre as pedagogias e suas inserções na educação é de grandiosa contribuição para a formação da consciência daqueles que defendem uma educação crítica e revolucionária. Do mesmo modo, precisamos avançar no domínio do que seria uma pedagogia com estas mesmas características, ou seja, precisamos compreender as necessidades, as possibilidades e a realidade com a qual esta proposta está comprometida.

\section{A pedagogia histórico-crítica no contexto de uma "revolução pedagógica"}

O problema central que impulsionou, no final da década de 1970 e início da década de 1980, a elaboração da pedagogia histórico-crítica foi a necessidade de se pensar meios do professor agir criticamente, vislumbrando um horizonte de mudanças sociais, nas condições que a realidade apresenta (SAVIANI, 2013). Ou seja, responder à questão: como é possível uma prática pedagógica crítica e transformadora considerando-se os limites impostos à ação educativa pela sociedade dividida em classes sociais?

Esta problemática emerge da insuficiência de uma resposta meramente negativa, colocada pelas teorias crítico-reprodutivistas. O que provocou Saviani a avançar em uma proposição dialética para a educação no fim da década de 70 .

Diante da insatisfação com essas análises crítico-reprodutivistas, foi avolumando-se a exigência de uma análise do problema educacional que desse conta de seu caráter contraditório, resultando em orientações com influxo na prática pedagógica, alterando-a e possibilitando sua articulação com os interesses populares em transformar a sociedade (SAVIANI, 2013, p. 61).

Saviani (2013, p. 61) explica que a teoria passou a ser denominada de "histórico-crítica" tendo em vista "reter o caráter crítico de articulação com as condicionantes sociais que a visão 
reprodutivista possui, vinculado, porém, à dimensão histórica que o reprodutivismo perde de vista". Ao defender a escola e o processo de ensino e de aprendizagem dos conteúdos, saberes escolares, a pedagogia histórico-crítica se torna alvo de críticas que a desqualificam como sendo conteudista, isto é, uma pedagogia centrada nos conteúdos e despreocupada com a forma, com os processos (SAVIANI, 2013; DUARTE, 2015).

No entanto, Saviani (2013) ressalta a importância da pedagogia como área que irá se preocupar com a forma, ou seja, o modo como os conteúdos são selecionados e ensinados, partindo da transformação dos saberes elaborados em saberes escolares. "Assim, a questão central da pedagogia é o problema das formas, dos processos, dos métodos; certamente, não considerados em si mesmos, pois as formas só fazem sentido quando viabilizam o domínio de determinados conteúdos" (SAVIANI, 2013, p. 65).

Portanto, interessa à concepção histórico-crítica, assim como à pedagogia em específico, refletir os métodos por meio dos quais o aluno irá se apropriar dos conhecimentos. Mais do que o acúmulo quantitativo de saberes, é preciso qualificar o que se ensina e se aprende, como e por quê. Neste sentido, é imprescindível a compreensão histórica do saber, pois, sua produção é social. Daí também a necessidade de nos apropriarmos daquilo que gerações anteriores já produziram para que assim possamos avançar e superar (por incorporação), de acordo com os interesses e finalidades da classe trabalhadora.

Uma pedagogia articulada com os interesses populares valorizará, pois, a escola; não será indiferente ao que ocorre em seu interior; estará empenhada em que a escola funcione bem; portanto, estará interessada em métodos de ensino eficazes. Tais métodos situar-se-ão para além dos métodos tradicionais e novos, superando por incorporação as contribuições de uns e de outros. Serão métodos que estimularão a atividade e iniciativa dos alunos sem abrir mão, porém, da iniciativa do professor; favorecerão o diálogo dos alunos entre si e com o professor, mas em deixar de valorizar o diálogo com a cultura acumulada historicamente; levarão em conta os interesses dos alunos, os ritmos de aprendizagem e o desenvolvimento psicológico, mas sem perder de vista a sistematização lógica dos conhecimentos, sua ordenação e gradação para efeitos do processo de transmissão-assimilação dos conteúdos cognitivos (SAVIANI, 2008, p. 55-56).

Compreender o movimento histórico-dialético da educação e da escola nesta sociedade é o objetivo basilar da pedagogia histórico-crítica para, a partir desta compreensão, contribuir propositadamente para uma pedagogia transformadora, em defesa da especificidade da escola, buscando evidenciar, historicamente, suas contradições e possibilidades. Tarefa que tem se tornado ainda mais necessária e urgente na atualidade.

O Brasil tem provocado um amplo movimento de mudanças na educação que 
corroboram com o discurso da melhoria da qualidade do ensino e adequação da educação básica, tecnológica e superior às demandas do mercado de trabalho, próprio das políticas neoliberais. Em 15 de outubro de 2019, o Ministério da Educação anuncia: "Das escolas cívicomilitares ao Future-se: os Novos Caminhos para os professores no governo Bolsonaro". O destaque é dado para o protagonismo dos professores na implementação e sucesso nos resultados dos programas desenvolvidos pelo governo federal para a educação no país (BRASIL, 2019a).

Os programas (Programa Nacional das Escolas Cívico-Militares, Future-se, Novos Caminhos) abrangem a educação básica, o ensino superior e a educação profissional e tecnológica, com objetivos alinhados a todas as dimensões do trabalho educativo, desde a prática pedagógica, gestão e produção de novos conhecimentos. Para nortear a formação docente também temos em curso a implementação da Proposta para a Base Nacional Comum para a Formação de Professores da Educação Básica (BNC-Professores).

De acordo com o Ministério da Educação,

A premissa da proposta da BNC-Professores são os recorrentes resultados insuficientes de aprendizagem dos estudantes e da baixa qualidade da formação dos docentes. Em geral, os cursos contam com muita teoria e pouca prática, falta aprofundamento no ensino para a educação infantil, alfabetização e anos iniciais, além de estágios curriculares sem planejamento e sem vinculação com as escolas (BRASIL, 2019b).

Tais políticas refletem as orientações internacionais para os países da América Latina para a adequação da educação básica, superior e profissional aos ditames e interesses neoliberais (SANTOS; ZANARDINI; MARQUES, 2020) e contribui para o avanço do senso comum neoliberal e obscurantista (DUARTE; MAZZEU; DUARTE, 2020). Neste ínterim não podemos deixar de ressaltar que enfrentamos mundialmente uma pandemia que trouxe como uma de suas consequências a explosão da educação à distância como recurso inovador e salvador de todos os problemas educacionais para a sociedade, sem levar em consideração a realidade social, que necessita e gera desigualdades nas condições de existência e de formação humana.

Além disso, a importância da educação escolar vem sendo constantemente secundarizada em relação a outros meios e espaços de educação, tais como, família, internet, experiências práticas e profissionais, minimizando sua efetiva contribuição para a apropriação de conhecimentos. No cenário atual, de pandemia e isolamento social, com a educação à distância e o ensino remoto, essa secundarização da escola tende a atingir limites destrutivos. 
A pedagogia histórico-crítica entende que a tendência a secundarizar a escola traduz o caráter contraditório que atravessa a educação, a partir da contradição da própria sociedade. Na medida em que estamos ainda numa sociedade de classes com interesses opostos e que a instrução generalizada da população contraria os interesses de estratificação de classes, ocorre essa tentativa de desvalorização da escola, cujo objetivo é reduzir o seu impacto em relação às exigências de transformação da própria sociedade (SAVIANI, 2013, p. 84).

Para se contrapor à perspectiva hegemônica de educação escolar e contribuir para o pleno desenvolvimento dos indivíduos, a pedagogia histórico crítica, segundo Saviani (1987), se defronta com uma dupla tarefa: uma negativa, cujo objetivo é criticar a concepção dominante de educação (desvalorização/esvaziamento do conhecimento escolar); e outra positiva, cujo objetivo é trabalhar o núcleo válido do senso comum, que seria o bom senso, desvinculando-o da ideologia dominante (que na atualidade é o neoliberalismo obscurantista ${ }^{4}$ ) e articulando-o a uma visão crítica da sociedade e da história, ou seja, aquilo que Saviani chamou de elevação das consciências do nível do senso comum ao da consciência filosófica. Sua finalidade, portanto, é contrapor a naturalização das relações sociais estabelecidas.

Foster (2019) analisou o capitalismo e seu declínio nos últimos anos, apontando o quanto as políticas neoliberais estão entrelaçadas ao modo de produção capitalista e a necessidade de sua superação por completo. Ou seja, o fortalecimento da luta social na direção de uma nova forma de organização diante da destruição das relações humanas e da natureza. Cenário que percebemos e sentimos no Brasil nos últimos anos com o avanço da ultradireita e os ataques à educação pública.

Neste sentido, as estratégias teórico-metodológicas marcam a pedagogia históricocrítica como uma concepção revolucionária, no sentido mais amplo de ruptura social. Trata-se de uma pedagogia cujo objetivo é produzir a humanidade nos indivíduos por meio de uma atividade intencional, sistematizada, voltada às formas mais adequadas de transmitir os conhecimentos científicos, artítiscos e filosóficos. Estes, por sua vez, não são dados constituídos a priori, pois, requerem sistematização e transposição didática, transformação destes conhecimentos em saberes escolares.

Assim, o objeto da educação diz respeito, de um lado, à identificação dos elementos culturais que precisam ser assimilados pelos indivíduos da espécie humana para que eles se tornem humanos e, de outro lado e concomitantemente, à descoberta das formas mais adequadas para atingir esse objetivo (SAVIANI, 1987, p. 13).

Neste ponto devemos salientar que, assim como afirmam Marsiglia e Martins (2018),

${ }^{4}$ Para análises sobre o neoliberalismo obscurantista ver Duarte, Mazzeu e Duarte (2020).

RIAEE - Revista Ibero-Americana de Estudos em Educação, Araraquara, v. 15, n. esp. 3, p. 2204-2222, nov. 2020. e-ISSN: 1982-5587 
em todos os processos educativos há uma forte tensão histórica entre humanização e alienação dos indivíduos, visto que precisamos considerar os elementos que compõem a sociedade. Acontece que quanto mais profundas e agudas se tornam as contradições da sociedade capitalista, menos interesse tem a ideologia dominante em permitir a socialização de conhecimentos que possibilitem o desenvolvimento de uma visão de mundo verdadeiramente dialética, materialista e histórica.

Trata-se, portanto, do combate por todos os meios à difusão da verdade pois, como explica Löwy (1994, p. 208), se a burguesia conseguiu chegar ao poder e impor uma forma de organização social sem necessidade de "uma consciência lúcida dos acontecimentos", o mesmo não pode ocorrer com a prática revolucionária do proletariado:

O proletariado, pelo contrário, não pode tomar o poder, transformar a sociedade e construir o socialismo senão por uma série de ações deliberadas e conscientes. O conhecimento objetivo da realidade, da estrutura econômica e social, da relação de forças e da conjuntura política é, portanto, uma condição necessária de sua prática revolucionária; em outras palavras: a verdade é uma arma de seu combate, que corresponde a seu interesse de classe e sem a qual ele não pode prosseguir (LÖWY, 1994, p. 208-209).

A escola tem como função principal, ou nas palavras de Saviani (2013, p. 15), tem como atividade nuclear, "a transmissão dos instrumentos de acesso ao saber elaborado". Entretanto, não é raro o objetivo de ensino pautado na transmissão de conhecimentos ser confundido entre a pedagogia tradicional e a pedagogia histórico-crítica, tanto no sentido de acusação desta, quanto de supervalorização daquela. Pasqualini e Lavoura (2020), ao debaterem as diferenças entre as duas propostas pedagógicas e apresentarem o caráter ontológico da pedagogia histórico-crítica, defendem a necessidade de superação da noção mecânica e acrítica de transmissão de conteúdos, o que provoca a errônea "ideia de que a escola que transmite arte, ciência e filosofia impõe um processo passivo e de coerção para os alunos” (p. 21).

A perspectiva histórico-crítica não está fundamentada em verbalismos presentes do ensino tradicional, nem mesmo no espontaneísmo dos métodos novos, próprios das pedagogias do aprender a aprender (PASQUALINI; LAVOURA, 2020). Não se trata de uma proposta abstrata, mas, de uma proposta que vincula à escola uma função concreta e aberta às contradições desta sociedade.

Isso implica uma visão dialética de determinação e superação dos limites impostos à educação. Não é, portanto, uma concepção determinista que compreende a educação apenas sob aspectos negativos e reprodutivistas. Essa visão dialética vincula-se à perspectiva histórica da realidade. Como proposta decorrente do materialismo histórico dialético, parte da categoria 
trabalho como elemento fundante do ser humano e, consequentemente elemento explicativo da educação escolar. O que permite

situar a especificidade de educação como referida aos conhecimentos, ideias, conceitos, valores, atitudes, hábitos, símbolos sob o aspecto de elementos necessários à formação da humanidade em cada indivíduo singular, na forma de uma segunda natureza, que se produz, deliberada e intencionalmente, através de relações pedagógicas historicamente determinadas que se travam entre os homens (SAVIANI, 1987, p. 20).

A educação como atividade intencionalmente voltada à produção da humanidade, requer sistematizações e transmissões a outros indivíduos singulares. Neste sentido, Duarte (1998) defende uma concepção afirmativa sobre o ato de ensinar, o que significa que é necessário atribuir ao trabalho pedagógico uma intencionalidade que rebata as concepções negativas sobre tal ato. Para a pedagogia histórico-crítica, o professor tem uma função central, a medida que contribui para apropriação das objetivações humanas que constituem o próprio gênero humano (DUARTE, 2013). A elevação do nível de conhecimento do ser humano, do senso comum ao conhecimento mais desenvolvido possibilita a reflexão crítica dos processos históricos e sociais da produção do gênero humano e das relações sociais que determinam a vida cotidiana (SAVIANI, 1987; DUARTE, 2013).

Segundo Duarte (2016, p. 67),

O conhecimento mais desenvolvido é aquele que permite a objetivação do ser humano de forma cada vez mais universal e livre. O critério é, portanto, o da plena emancipação humana. Em termos educativos, há que se identificar quais conhecimentos podem produzir, nos vários momentos do desenvolvimento pessoal, a humanização do indivíduo.

Neste sentido, o pensamento filosófico crítico, a reflexão sobre a atividade social para além do imediatismo pragmático cotidiano, são necessidades imperativas para a classe trabalhadora, mesmo que boa parte dos indivíduos que a compõem na atualidade possa não ter consciência dessa necessidade. O ensino dos conceitos tomando como base os conhecimentos sistematizados, pautados na ciência, na filosofia e na arte, é uma condição para a superação dos conhecimentos espontâneos, alicerçados no cotidiano. Neste movimento, de superação da espontaneidade cotidiana alienada, o ser humano se apropria de saberes que se integrarão à sua personalidade, passando a ser elementos constitutivos da mesma, possibilitando a transformação da visão que o indivíduo tem do mundo.

O que não quer dizer que os conceitos sistematizados estão em negação pura e simples em relação aos provenientes da prática imediata, pois, 
Os conceitos científicos teriam, segundo Vigotski, quando comparados aos conceitos espontâneos, a força dada por sua alta capacidade de síntese, de sistematização e de generalização. A fraqueza dos conceitos científicos estaria, porém, em seu caráter abstrato. Já os conceitos espontâneos teriam a força de sua proximidade imediata ao objeto, dando-lhe mais concretude, mas teriam a fraqueza de sua limitação, sua falta de sistematicidade e sua incapacidade de ir além das aparências. Sem os conceitos espontâneos, a criança e o adolescente não seriam capazes de adquirir os conceitos científicos, mas sem este seu pensamento se tornaria prisioneiro da imediatez da vida cotidiana (DUARTE, 2016, p. 69-70).

A tarefa da transmissão destes conceitos cabe, portanto, aos professores nas escolas, para que o aluno tenha a oportunidade de compreender a realidade e superar a visão do senso comum. Ademais, "a apropriação de conceitos e teorias é feita a partir dos interesses, da visão de mundo e da posição que os indivíduos ocupam no quadro social” (SAVIANI, 2013, p. 72). Ainda que o conhecimento sistematizado não seja do interesse imediato do aluno, é tarefa do professor mediá-lo para a apropriação do mesmo.

Os conceitos científicos se manifestam em uma esfera subjugada à orientação conscientemente dirigida, à voluntariedade, esfera que se mostra extremamente frágil na adoção de conceitos cotidianos, orientados fundamentalmente por sua aplicação imediata e pragmática. O caráter consciente e volitivo da formação dos conceitos científicos, propriedades insuficientemente mobilizadas pelos conceitos espontâneos, institui-se, segundo Vigotski, na completa dependência da colaboração participativa do pensamento do adulto - conformando-se, pois, na zona de desenvolvimento iminente $^{5}$ (MARTINS, 2013, p. 223).

É importante pensar o trabalho do professor neste âmbito da mediação ${ }^{6}$, já que o professor é responsável pela transmissão dos conhecimentos que, por sua vez, farão a mediação entre aluno e realidade. É neste sentido que Saviani (2013) defende o ensino dos conteúdos clássicos na educação escolar. Não na direção da reprodução da forma alienada de ver a

\footnotetext{
${ }^{5} \mathrm{Na}$ teoria psicológica de Vigotski, as funções psíquicas nascem nas relações sociais, portanto, como funções interpsíquicas para, depois, se internalizarem, transformando-se em funções intrapsíquicas. Nesse processo, quando as funções psíquicas ainda não se internalizaram, a criança não as põe em funcionamento de maneira autônoma, mas sim na atividade com o adulto, sendo por este guiada, ensinada, orientada. Com frequência são funções que são postas em movimento por processos imitativos. Aos poucos a criança vai conquistando a capacidade de colocar essas funções em ação por si mesma, de forma relativamente autônoma e elas se internalizam. A zona de desenvolvimento iminente é justamente constituída pelas funções que ainda estão por serem internalizadas, ou seja, ainda estão em processo de formação. Vigotski defendia que as ações educativas deveriam incidir exatamente sobre a zona de desenvolvimento iminente.

${ }^{6} \mathrm{O}$ uso da categoria de mediação para caracterizar a educação escolar como "mediação no seio da prática social global" (SAVIANI, 2008) é totalmente distinto da acepção construtivista do professor como mediador. Esta segunda, ao afirmar que o professor é mediador, visa descaracterizar sua atividade como sendo a de ensinar, de transmitir o conhecimento.
} 
sociedade, mas, como salientou Duarte (2016), a reprodução, neste contexto, é elevada ao nível da apropriação e enriquecimento da subjetividade humana.

Uma pedagogia revolucionária que tenha como objetivo instrumentalizar o ser humano não está calcada em um processo de ensino meramente instrumental, mas sim, de universalização, desenvolvimento da capacidade de pensamento crítico e do enriquecimento da individualidade. Neste sentido, Duarte (2016), chama a atenção para a necessidade de, na perspectiva da pedagogia histórico-crítica, reconhecermos a reprodução da humanidade no indivíduo em contraposição à ideia de reproduzir as formas capitalistas de existência. Para tanto, a humanização do ser social é o pressuposto da reprodução e o objetivo da transmissão dos conhecimentos.

Ao longo deste processo, é imprescindível que haja uma síntese daquilo que foi apropriado ao nível da consciência, o que na concepção gramsciana conhecemos como catarse. Segundo Saviani (2008), a catarse diz respeito à incorporação dos instrumentos culturais de tal forma que se tornam novos elementos para a transformação social (SAVIANI, 2008).

Duarte (2019, p. 18) compreende a catarse como "uma produção de necessidades que apontam para a ampliação do universo das relações sociais nas quais o indivíduo está inserido, bem como para um novo posicionamento do indivíduo perante a realidade da qual ele faz parte", ou seja, um avanço qualitativo nas relações entre a subjetividade individual e a objetividade sociocultural.

As mudanças neste processo podem ocorrer de modo parcial, pois a catarse não se efetiva drasticamente e de forma homogênea da noite para o dia. Do mesmo modo que a superação da alienação nem sempre é um processo visível de ruptura. A catarse para Duarte, Ferreira e Anjos (2012, p. 11), "é esse impulso em direção à suspensão, mesmo que momentânea, do imediatismo da vida cotidiana e do fetichismo que nela predomina”. Por este motivo o professor e a escola têm papel fundamental na mediação entre os indivíduos e as objetivações humanas para que possa se desenvolver a catarse.

A partir da catarse o aluno atinge uma compreensão mais complexa e abrangente do todo, superando a visão sincrética e fragmentada, permitindo a explicação do real e a ação consciente e significativa sobre ele. Assim, ao avançar da síncrese para a síntese e ter a possibilidade de compreender os fenômenos em sua totalidade, o aluno alcança outro nível de consciência e compreensão do mundo (qualitativa e quantitativamente superior).

A pedagogia histórico-crítica, porém, não considera a transformação das consciências como um fenômeno independente da prática social e isolado em si mesmo. A definição de educação como mediação no seio da prática social parte da tese marxista da unidade entre 
transformação revolucionária da realidade social e dos sujeitos da práxis revolucionária. Marx, na terceira tese sobre Feuerbach, faz uma crítica à ideia de que a perspectiva materialista sobre a necessidade de transformação da sociedade possa atingir as pessoas apenas por meio de processos de educação das consciências. Paradoxalmente, essa visão de educação das pessoas, pretendendo a difusão de uma concepção materialista, acaba por adotar uma premissa idealista, a de que a mudança da sociedade e da vida seria um processo limitado ao plano das consciências.

É nesse sentido que Marx considerava insuficiente a crítica de Feuerbach ao cristianismo. Ambos concordavam que o deus dos cristãos, assim como todos os deuses de todas as religiões, é uma criação humana. Marx, porém, entendia que a superação dessa alienação dos seres humanos nos deuses não se supera apenas pela crítica filosófica, sendo necessário superar o tipo de sociedade que faz com que as pessoas vivam e se relacionem de determinadas maneiras geradoras tanto da alienação religiosa como de outras formas de alienação. Em outras palavras, a transformação dos sujeitos não precede a transformação da realidade social e vice-versa. Trata-se de um processo dialético no qual os dois polos se transformam em ação recíproca:

A doutrina materialista sobre a modificação das circunstâncias e da educação esquece que as circunstâncias são modificadas pelos homens e que o próprio educador tem que ser educado. Ela tem, por isso, de dividir a sociedade em duas partes - a primeira das quais está colocada acima da sociedade. A coincidência entre a alteração das circunstâncias e a atividade ou automodificação humana só pode ser apreendida e racionalmente entendida como prática revolucionária (MARX, 2007, p. 533-534, grifo do autor).

Isto significa dizer que a luta de classes não poderá acontecer idealmente.

\section{Considerações finais}

Pesquisas como a de Fernandes e Franco (2019) e de Almeida, Barros e Rabal (2019) mostram que o professor, na busca pela superação da alienação em seu trabalho, necessita basear-se em uma perspectiva pedagógica, histórica e social que se posicione perante a luta de classes e considere a categoria da contradição na dinâmica das instituições de ensino, das políticas públicas e do trabalho educativo. Ou seja, uma perspectiva que tenha como objetivo a superação das relações capitalistas, sem deixar de considerar as inúmeras contradições que existem na realidade e que constituem o próprio processo de transformação. 
Por este motivo, para que a pedagogia histórico-crítica possa avançar na direção da transformação da sociedade dividida em classes sociais, é preciso sua efetiva incorporação como uma teoria pautada na concepção de mundo do materialismo histórico-dialético, de modo que esta passe a nortear os processos de formação da individualidade e constituir as relações na prática educativa. Sendo assim, acreditamos ser primordial pensarmos o significado que tem para o próprio professor a realidade que vivemos e a tarefa de formar seres humanos. $\mathrm{O}$ professor, por sua vez, também precisa ter superada a visão de mundo pautada no senso comum para auxiliar na construção de uma hegemonia emancipadora.

A concepção de mundo do professor faz a mediação entre a teoria que se aceita, defende, acredita, e a ação educativa, a prática do ensino. Entretanto, é preciso compreendermos a relação dialética entre teoria e prática que sustenta tal concepção de mundo e as condições materiais que dão suporte para a ação prática, visto que a materialidade da ação educativa é um fundamento da pedagogia histórico-crítica.

Sobre esta questão, Saviani (2013) aponta três grandes desafios para a educação: a elaboração de um sistema nacional de educação, a reestruturação organizacional da prática para a efetivação de uma nova teoria que se propõe e a necessidade da continuidade no trabalho a tal ponto que a persistência cause a irreversibilidade, caso contrário, os objetivos podem não ser atingidos. De acordo com o autor, "difundir uma concepção implica sua incorporação no nível de senso comum, desnaturando em vários aspectos o que é pressuposto" (SAVIANI, 2013, p. 73-74).

Dentre estes problemas e desafios está a situação precária pela qual a escola tem passado há muitos anos, desde as condições de trabalho, salários defasados, jornadas longas e, a própria formação dos professores. O que reflete em problemas para a própria efetivação da teoria que defendemos:

Em tais condições, fica difícil para esses professores assimilar as propostas teóricas e procurar implementá-las na sua prática. Evidencia-se aí um quadro de precariedade que repercute na teoria, colocando óbices para o seu desenvolvimento e para a verificação do grau em que as propostas teóricas de fato podem ser alternativas para um trabalho qualitativo pedagogicamente diferenciado (SAVIANI, 2013, p. 98-99).

Ao mesmo tempo que tais condições colocam em suspenso (ou marcha lenta) o desenvolvimento e efetivação integral da pedagogia histórico-crítica, também nos instigam à, ao tomarmos consciência dos desafios da prática, pensar e assumir atitudes e mecanismos de resistência para a superação das dificuldades, como o próprio precursor da proposta salienta. Finalizamos acrescentando que esta tarefa é histórica e requer uma constante avaliação para 
união de esforços que contribuam para que se fortaleça como uma pedagogia verdadeiramente revolucionária, portanto, coerente, crítica e emancipadora.

\section{REFERÊNCIAS}

ALMEIDA, J. D. F.; BARROS, M. S. F.; RABAL, T. S. Formação e ação docente na perspectiva sócio-histórica: um olhar para humanização dos sujeitos na educação. Revista Ibero-Americana de Estudos em Educação, Araraquara, v. 14, n. 1, p. 108-122, jan./mar. 2019. E-ISSN: 1982-5587. DOI: https://doi.org/10.21723/riaee.v14i1.11143

BATISTA, E. L.; LIMA, M. R. A pedagogia histórico-crítica como teoria pedagógica transformadora: da consciência filosófica à prática revolucionária. In: MARSIGLIA, A. C. G.; BATISTA, E. L. (Org.). Pedagogia histórico-crítica: desafios e perspectivas para uma educação transformadora. Campinas, SP: Autores Associados, 2012. p. 1-36.

BRASIL. Ministério da Educação. Das escolas cívico-militares ao future-se: os novos caminhos para os professores no governo Bolsonaro. 2019a. Disponível em: http://portal.mec.gov.br/component/content/article?id=81241. Acesso em: 26 ago. 2020.

BRASIL. Ministério da Educação. Base Nacional para formação do professor vai revisar cursos para conhecimento e valorização. 2019b. Disponível em:

http://portal.mec.gov.br/component/content/article/211-noticias/218175739/71951-basenacional-para-formacao-do-professor-vai-revisar-cursos-para-conhecimento-evalorizacao?Itemid=164. Acesso em: 26 ago. 2020.

DUARTE, N. A individualidade para - si: contribuição à uma teoria histórico-social da formação do indivíduo. 3. ed. rev. Campinas, SP: Autores Associados, 2013.

DUARTE, N. A importância da concepção de mundo para a educação escolar: porque a pedagogia histórico-crítica não endossa o silêncio de Wittgenstein. Germinal: marxismo e educação em debate, Salvador, v. 7, n. 1, p. 8-25, jun. 2015. Disponível em https://portalseer.ufba.br/index.php/revistagerminal/article/view/12808/9501. Acesso em: 10 ago. 2020.

DUARTE, N. Os conteúdos escolares e a ressurreição dos mortos. Campinas, SP: Autores Associados, 2016.

DUARTE, N. A catarse na didática da pedagogia histórico-crítica. Pro-Posições, Campinas, v. 30, e20170035, 2019. Disponível em:

http://www.scielo.br/scielo.php?script=sci_arttext\&pid=S0103-

73072019000100201\&lng=pt\&nrm=iso. Acesso em: 10 ago. 2020. DOI: https://doi.org/10.1590/1980-6248-2017-0035

DUARTE, N.; FERREIRA, N. B. P.; ANJOS, R. E. O conceito ético-político de catarse e a importância da adolescência para a formação humana. In: REUNIÃO ANUAL DA ANPED, 35., 2012, Porto de Galinhas. Anais [...]. Porto de Galinhas/PE: Associação Nacional de PósGraduação e Pesquisa em Educação, 2012. p. 01-16. 
DUARTE, N.; MAZZEU, F. J. C.; DUARTE, E. C. M. O senso comum neoliberal obscurantista e seus impactos na educação brasileira. Revista on line de Política e Gestão Educacional, Araraquara, v. 24, n. esp. 1, p. 715-736, ago. 2020. Disponível em: https://periodicos.fclar.unesp.br/rpge/article/view/13786. Acesso em: 26 ago. de 2020.

FERNANDES, G. F. G.; FRANCO, S. A. P. Reflexão e ação: a pedagogia histórico-crítica e suas possiblidades em grupo de estudo com professores de Língua Portuguesa. Revista Ibero-Americana de Estudos em Educação, Araraquara, v. 14, n. 4, p. 2141-2159, out./dez. 2019. e-ISSN: 1982-5587. DOI: https://doi.org/10.21723/riaee.v14i4.10408

FOSTER, J. B. Capitalism has failed: what next? Monthly Review, v. 70, n. 9, fev. 2019. Disponível em: https://monthlyreview.org/2019/02/01/capitalism-has-failed-what-next/. Acesso em: 26 ago. 2020.

GRAMSCI, A. Cadernos do Cárcere. 4. ed. Rio de Janeiro: Civilização Brasileira, 2011. v. 3 .

LENINE, V. I. Sobre a educação. Lisboa: Seara Nova, 1977. v. 1.

LÖWY, M. As aventuras de Karl Marx contra o Barão de Münchhausen. 4. ed. São Paulo, Cortez, 1994.

MARSIGLIA, A. C. G.; MARTINS, L. M. A natureza contraditória da educação escolar: tensão histórica entre humanização e alienação. Revista IberoAmericana de Estudos em Educação, Araraquara, v. 13, n. 4, p. 1697-1710, out./dez., 2018. E-ISSN: 1982-5587. DOI: https://doi.org/10.21723/riaee.unesp.v13.n4.out/dez.2018.10265

MARTINS, L. M. Pedagogia histórico-crítica e psicologia histórico-cultural. In:

MARSIGLIA, A. C. G. (Org). Pedagogia histórico-crítica: 30 anos. Campinas, SP: Autores Associados, 2011. p. 43-57.

MARTINS, L. M. O desenvolvimento do psiquismo e a educação escolar: contribuições à luz da psicologia histórico-cultural e da pedagogia histórico-crítica. Campinas, SP: Autores Associados, 2013.

MARX, K. Ad Feuerbach (1845). In: MARX, K.; ENGELS, F. A ideologia alemã: crítica da mais recente filosofia alemã em seus representantes Feuerbach, B. Bauer e Stirner, e do socialismo alemão em seus diferentes profetas (1845-1846). São Paulo: Boitempo, 2007.

PASQUALINI, J. C.; LAVOURA, T. N. A transmissão do conhecimento em debate: estaria a pedagogia histórico-crítica reabilitando o ensino tradicional? Educação em Revista, Belo Horizonte, v. 36, e221954, 2020. Disponível em:

file://E:/Leituras/PHC\%20e\%20o\%20ensino\%20tradicional\%20Pasqualini $\% 20 \mathrm{e} \% 20 \mathrm{Lavoura}$ .pdf. Acesso em: 18 ago. 2020.

SANTOS, F. A.; ZANARDINI, J. B.; MARQUES, H. J. Desafios políticos, econômicos e sociais para os docentes na América Latina. Revista on line de Política e Gestão Educacional, Araraquara, v. 24, n. esp. 1, p. 794-815, ago. 2020. Disponível em: https://periodicos.fclar.unesp.br/rpge/article/view/13781/9383. Acesso em: 26 ago. 2020. 
SAVIANI, D. As teorias da educação e o problema da marginalidade na América Latina. Cadernos de Pesquisa, São Paulo, n. 42, p. 08-18, ago. 1982. Disponível em: http://publicacoes.fcc.org.br/ojs/index.php/cp/article/view/1546/1545. Acesso em: 10 de ago de 2020.

SAVIANI, D. Educação: do senso comum à consciência filosófica. São Paulo: Cortez e Autores Associados, 1987.

SAVIANI, D. Escola e Democracia: teorias da educação, curvatura da vara, onze teses sobre a educação política. Edição Comemorativa. Campinas, SP: Autores Associados, 2008.

SAVIANI, D. Pedagogia Histórico-Crítica: primeiras aproximações. 11. ed. rev. Campinas, SP: Autores Associados, 2013.

VARGAS, M.; WETERMAN, D. Governo tenta adiar votação do Fundeb em uma semana. UOL. 20 de jul. de 2020. Cotidiano. Disponível em: https://noticias.uol.com.br/ultimasnoticias/agencia-estado/2020/07/20/governo-tenta-adiar-votacao-do-fundeb-em-umasemana.htm. Acesso em: 18 ago. 2020.

\section{Como referenciar este artigo}

MARQUES, H. J.; DUARTE, N. A Pedagogia Histórico-Crítica em defesa de uma educação revolucionária. Revista Ibero-Americana de Estudos em Educação, Araraquara, v. 15, n. esp. $\quad 3$, p. 2204-2222, nov. 2020. e-ISSN: 1982-5587. DOI: https://doi.org/10.21723/riaee.v15iesp3.14427

Submetido em: 20/07/2020

Revisões requeridas em: $30 / 08 / 2020$

Aprovado em: 29/09/2020

Publicado em: $30 / 10 / 2020$ 